\title{
Scl-70 IgG Antibody Measurement
}

National Cancer Institute

\section{Source}

National Cancer Institute. Scl-70 Ig G Antibody Measurement. NCI Thesaurus. Code C122148.

The determination of the amount of Scl-70 IgG antibody in a biological specimen. 